\title{
Rapid positioning of nasogastric tube by ultrasound in COVID-19 patients
}

\author{
Anyu Qian, Shanxiang Xu, Xiao Lu, Luping Tang, Mao Zhang ${ }^{*}$ (D) and Xiao Chen
}

Keywords: COVID-19, ultrasound, nasogastric tube

\section{Dear editor,}

It is well known that early enteral nutrition therapy is one of the basic management for critically ill COVID-19 patients. Nasogastric tube (NGT) is the most common access for enteral nutrition, and the correct positioning of NGT is a prerequisite. Otherwise, the malposition may result in severe complications, including asphyxia and pneumonia.

The pandemic of COVID-19 caused the overload of local medical service system, especially intensive care resources, such as ICU beds, ventilators, and intensivists. On February 14, a critical care team including 42 doctors, 123 nurses, and 6 logistical staffs from the Second Affiliated Hospital of Zhejiang University (SAHZU) was dispatched to Wuhan to take over a temporary ICU and admitted 61 critically ill patients with COVID19. The positioning of NGT became one of big challenges. Bedside radiography which is the standard method of positioning NGT was not accessible in time in the temporary ICU. The traditional method is auscultating for sounds by stethoscope in the epigastrium while injecting air into NGT, but it is unreliable $[1,2]$. Furthermore, the stethoscope is difficult to use due to the strict personal prevention of medical staff. Measuring $\mathrm{PH}$ value of gastric juice is an alternative method, but sometimes, it was not available, while monitoring end-tidal carbon dioxide by NGT can only exclude the malposition of NGT in airway [3, 4]. Some studies reported the role of ultrasound in positioning NGT [4], especially in settings where X-ray is not readily available, and ultrasound may be useful to detect misplaced gastric tubes [5]. Therefore, we tried to confirm the right place of NGT by ultrasound for these COVID-19 patients.

We introduced a specific procedure for rapid positioning NGT, based on the use of a portable ultrasound (M9, Mindray CO. LTD, China). The probe was oriented towards the left upper abdominal quadrant to visualize the gastric area. If 2 parallel hyperechogenic lines were seen through cardia, or ultrasound image showed dynamic hyperechogenic air area in the stomach when $20 \mathrm{ml}$ of air was injected through the NGT (Fig. 1), correct positions of NGT could be confirmed. Two other traditional methods were also combined, one was to place the end of the gastric tube in water and observe bubbles and the other was to observe gastric juice extraction. After confirming the right position of NGT by these three methods, we initiated enteral nutrition. We performed this procedure in 10 patients with COVID-19 requiring enteral nutrition, which had an average BMI of $22.8 \pm 1.9$. Ultrasound images of 9 patients showed dynamic hyperechogenic area or 2

\footnotetext{
* Correspondence: z2jzk@zju.edu.cn

Department of Emergency Medicine, The Second Affiliated Hospital of

Zhejiang University, School of Medicine, Hangzhou 310009, China
} 


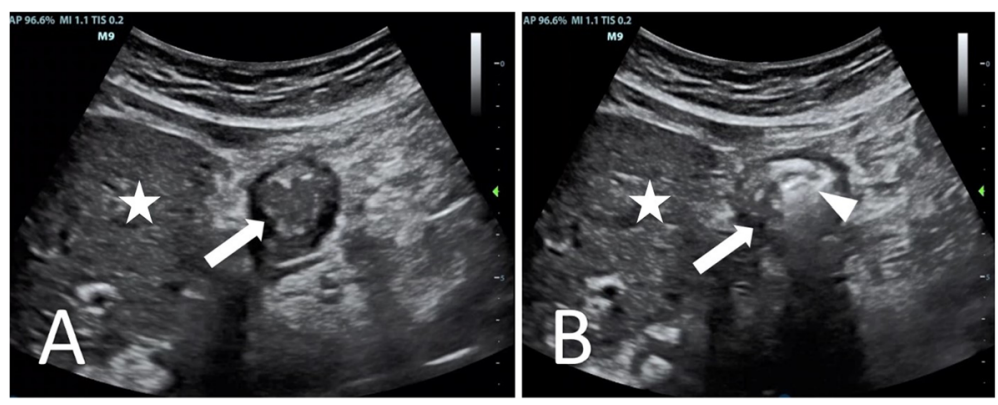

Fig. 1 Male, 52 years old, with the chief complain "cough for 1 week and chest distress for 2 days." A gastric tube was put. a Ultrasound showed the stomach (white arrow) and the liver (white star). b And then $20 \mathrm{ml}$ of air was injected through the NGT; ultrasound showed dynamic hyperechogenic air shadow in the stomach (white triangle)

parallel hyperechogenic lines in the stomach. In one patient, we could find neither of these signs, and then the NGT was found coiled in the throat and mouth. After it was reset, ultrasound scanning confirmed the right position in stomach.

In our opinion, the use of ultrasound is essential in coupling with COVID-19 pandemic, especially lung ultrasound, which has been further confirmed [6]. We introduced another application of ultrasound during COVID-19 outbreaks, which might help to confirm the position of NGT in this special setting. There were some limitations in our report. The BMIs of the cases was not high, so it was easy for ultrasound observation. However, it might be difficult to find NGT by this way in obesity or flatulence patients, and the experience of operators could also influence the performance. And the sample of this report was small; a larger study is needed to verify the effectivity and safety of this method.

\section{Acknowledgements}

We thank all the physicians and nurses in our medical team to help Wuhan in this epidemic.

\section{Authors' contributions}

Anyu Qian, Shanxiang Xu, Xiao Lu, Luping Tang, and Mao Zhang contributed to the data collection and writing and revision of the paper. Xiao Chen contributed to the revision and polishing the language of the paper. The authors read and approved the final manuscript.

Funding

No funding was used.

\section{Availability of data and materials}

The corresponding author had full access to the data and had final responsibility for the decision of submitting for publication.

\section{Ethics approval and consent to participate}

This study has been approved by the ethics committee in the Second Affiliated Hospital of Zhejiang University School of Medicine (Hangzhou, China) and performed in accordance with the ethical standards.

\section{Consent for publication}

All authors have read the complete manuscript and have approved submission of the paper.
Received: 31 May 2020 Accepted: 14 September 2020

Published online: 22 September 2020

\section{References}

1. Metheny NA, Stewart BJ, Mills AC. Blind insertion of feeding tubes in intensive care units: a national survey. Am J Crit Care. 2012;21:352-60. https://doi.org/10.4037/ajcc2012549.

2. Erzincanli S, Zaybak A, Güler A. Investigation of the efficacy of colorimetric capnometry method used to verify the correct placement of the nasogastric tube. Intensive Crit Care Nurs. 2017;38:46-52. https://doi.org/10. 1016/j.iccn.2016.08.005.

3. Chau JP, Lo SH, Thompson DR, Fernandez R, Griffiths R. Use of end-tidal carbon dioxide detection to determine correct placement of nasogastric tube: a meta-analysis. Int J Nurs Stud. 2011;48:513-21. https://doi.org/10. 1016/j.jijnurstu.2010.12.004.

4. Atalay YO, Aydin R, Ertugrul O, Gul SB, Polat AV, Paksu MS. Does bedside sonography effectively identify nasogastric tube placements in pediatric critical care patients? Nutr Clin Pract. 2016;31:805-9. https://doi.org/10.1177/ 0884533616639401

5. Tsujimoto H, Tsujimoto Y, Nakata Y, Akazawa M, Kataoka Y. Ultrasonography for confirmation of gastric tube placement. Cochrane Database Syst Rev. 2017;4(4):CD012083. https://doi.org/10.1002/14651858.CD012083.pub2.

6. Vetrugno L, Bove T, Orso D, Barbariol F, Bassi F, Boero E, Ferrari G, Kong R. Our Italian experience using lung ultrasound for identification, grading and serial follow-up of severity of lung involvement for management of patients with COVID-19. Echocardiography. 2020;37(4):625-7. https://doi.org/10.1111/ echo. 14664

\section{Publisher's Note}

Springer Nature remains neutral with regard to jurisdictional claims in published maps and institutional affiliations.

Ready to submit your research? Choose BMC and benefit from:

- fast, convenient online submission

- thorough peer review by experienced researchers in your field

- rapid publication on acceptance

- support for research data, including large and complex data types

- gold Open Access which fosters wider collaboration and increased citations

- maximum visibility for your research: over $100 \mathrm{M}$ website views per year

At BMC, research is always in progress.

Learn more biomedcentral.com/submissions 